\title{
Differential serum protein markers and the clinical severity of asthma
}

This article was published in the following Dove Press journal:

Journal of Asthma and Allergy

25 April 2014

Number of times this article has been viewed

\author{
Norbert Meyer ${ }^{1,2}$ \\ Sarah Janine Nuss' \\ Thomas Rothe' \\ Alexander Siebenhüner' \\ Cezmi A Akdis² \\ Günter Menz' \\ 'Hochgebirgsklinik Davos, Davos- \\ Wolfgang, Switzerland; ${ }^{2}$ Swiss Institute \\ of Allergy and Asthma Research \\ (SIAF), Davos Platz, Switzerland
}

Correspondence: Norbert Meyer; Günter Menz

Hochgebirgsklinik Davos,

Herman-Burchard-Str I, 7265

Davos-Wolfgang, Switzerland

Tel +4 I 0814174444

Fax +4I 08I 4173030

Email norbert.meyer@insel.ch;

guenter.menz@hgk.ch
Background: Asthma is a heterogeneous disease characterized by different clinical phenotypes and the involvement of multiple inflammatory pathways. During airway inflammation, many cytokines and chemokines are released and some are detectable in the sera.

Objective: Serum chemokines and cytokines, involved in airway inflammation in asthma patients, were investigated.

Methods: A total of 191 asthma patients were classified by hierarchical cluster analysis, including the following parameters: forced expiratory volume in 1 second $\left(\mathrm{FEV}_{1}\right)$, eosinophil cationic protein (ECP) serum levels, blood eosinophils, Junipers asthma symptom score, and the change in $\mathrm{FEV}_{1}$, ECP serum levels, and blood eosinophils after 3 weeks of asthma therapy. Serum proteins were measured by multiplex analysis. Receiver operating characteristic (ROC) curves were used to evaluate the validity of serum proteins for discriminating between asthma clusters.

Results: Classification of asthma patients identified one cluster with high ECP serum levels, increased blood eosinophils, low $\mathrm{FEV}_{1}$ values, and good $\mathrm{FEV}_{1}$ improvement in response to asthma therapy ( $\mathrm{n}=60$ ) and one cluster with low ECP serum levels, low numbers of blood eosinophils, higher $\mathrm{FEV}_{1}$ values, and no $\mathrm{FEV}_{1}$ improvement in response to asthma therapy $(\mathrm{n}=131)$. Serum interleukin (IL)-8, eotaxin, vascular endothelial growth factor (VEGF), cutaneous T-cell-attracting chemokine (CTACK), growth-related oncogene (GRO)- $\alpha$, and hepatocyte growth factor (HGF) were significantly different between the two clusters of asthma patients. ROC analysis for serum proteins calculated a sensitivity of $55.9 \%$ and specificity of $75.8 \%$ for discriminating between them.

Conclusion: Serum cytokine and chemokine levels might be predictors for the severity of asthmatic inflammation, asthma control, and response to therapy, and therefore might be useful for treatment optimization.

Keywords: asthma, cluster, phenotype, serum cytokines

\section{Introduction}

Asthma is a chronic inflammatory disorder of the airways, characterized by reversible airflow obstruction, airway hyper-responsiveness, and typical clinical symptoms such as wheezing, breathlessness, and chest tightness as a result of inflammation in the airways. The heterogeneity of the clinical presentation of asthma patients suggests that different inflammatory pathways play a role in the pathogenesis of asthma. ${ }^{1}$ Many cell types, including immune cells and tissue cells, are involved in asthmatic inflammation, and several molecular and cellular pathways are activated for the release of chemokines and cytokines. ${ }^{2}$ In allergic asthma, allergen-specific T-helper (Th)-2 lymphocytes release interleukin (IL)-4, -9 , and -13 , which are essential for the production of allergen-specific immunoglobulin $\mathrm{E}(\mathrm{IgE}){ }^{3} \mathrm{IgE}$ binding on the high-affinity $\mathrm{FC} \varepsilon$ receptor 1 (FceR1) 
activates mast cells and eosinophils, which subsequently secrete inflammatory mediators. ${ }^{4}$ These mediators cause bronchial smooth muscle contraction and increase airway hyper-reactivity, a cardinal feature of asthma. ${ }^{5}$ Additionally, other effector T-cell subsets, like Th1 or Th17 cells, can contribute to airway inflammation. ${ }^{6}$ Th17 cells are thought to be mainly involved in rhinovirus-induced asthma ${ }^{7}$ and neutrophil recruitment to the airways, ${ }^{8}$ whereas Th1 cells are important for induction of apoptosis in tissue cells. ${ }^{9}$

The identification of inflammatory proteins that are specific for clinical asthma phenotypes is one important approach to facilitate the diagnosis, therapy, and monitoring of asthma. Recently, it was demonstrated that the presence of serum IL-8, vascular endothelial growth factor (VEGF), and metalloproteinase-9 was associated with diisocyanateinduced asthma. ${ }^{10}$ In addition, increased IL-17 levels in sera of patients with severe asthma were described, ${ }^{11}$ and an association between serum IL-32 levels and treatment response in asthma patients was demonstrated. ${ }^{12}$ Moreover, differences in serum cytokine levels between allergic and non-allergic asthma have been demonstrated. ${ }^{13}$

In this study, we investigated serum and chemokine levels in 191 asthma patients who were classified into two groups according to several clinical and physiological parameters and the response to asthma therapy. Our hypotheses were that these two clinically different groups of asthma patients are characterized by different cytokine and chemokine serum levels and that the upregulation of cytokine and chemokine serum levels might indicate poorly controlled asthma.

\section{Methods}

\section{Study design}

Adult patients had a physician diagnosis of asthma according to Global Strategy for Asthma Management and Prevention, Global Initiative for Asthma (GINA) guidelines. To exclude chronic obstructive pulmonary disease, asthma patients had to show a reversibility in forced expiratory volume in 1 second $\left(\mathrm{FEV}_{1}\right)$ in response to a short-acting $\beta 2$-agonist of at least $12 \%$ predicted. Asthma patients with an acute respiratory infection were excluded. All asthma patients included in the study were admitted to, and treated for at least 3 weeks at, the high-altitude clinic Davos-Wolfgang, which is located 1,600 $\mathrm{m}$ above sea level in the Swiss Alps. The patients were admitted for a rehabilitation and asthma treatment optimization program and were treated according to the recent GINA guidelines; there were no acute hospitalizations. All medications related to asthma treatment and changes to it during the stay in the high-altitude clinic are shown in Table 1. To

Table I Characterization of asthma patients

\begin{tabular}{|c|c|c|c|c|c|}
\hline Parameters & Cluster I & Cluster 2 & Unpaired $t$-test & $\begin{array}{l}\text { Pearson's } \\
\text { chi-squared test }\end{array}$ & Number \\
\hline Allergic asthma & $70.0 \%$ & $80.2 \%$ & & 0.122 & 191 \\
\hline Age (years) & $54.4 \pm 12.0(2 \mid-79)$ & $48.1 \pm 15.9(18-80)$ & 0.003 & & 191 \\
\hline Age of onset (years) & $23.2 \pm 17.5(0-52)$ & $24.2 \pm 16.8(0-65)$ & 0.718 & & 191 \\
\hline Sex (male) & $43.3 \%$ & $44.3 \%$ & & 0.903 & 191 \\
\hline Smoker & $5.0 \%$ & $3.1 \%$ & & 0.506 & 191 \\
\hline Pack years & $4.2 \pm 6.8(0-30)$ & $4.0 \pm 7.3(0-35)$ & $0.87 I$ & & 191 \\
\hline BMI $\left(\mathrm{kg} / \mathrm{m}^{2}\right)$ & $24.8 \pm 4.1(\mid 7.0-39.0)$ & $25.7 \pm 3.8(19.0-36.0)$ & 0.129 & & 191 \\
\hline ATS criteria & $56.7 \%$ & $18.3 \%$ & & $<0.001$ & 191 \\
\hline $\begin{array}{l}\text { Exacerbations during } \\
\text { last year }\end{array}$ & $5.4 \pm 3.5$ & $3.8 \pm 3.0$ & 0.004 & & 191 \\
\hline Asthma control (\%) & & & & & 191 \\
\hline NC & 71.7 & 32.1 & & & \\
\hline PC & 25.0 & 40.5 & & & \\
\hline $\mathrm{FC}$ & 3.3 & 27.5 & & & \\
\hline Adherence to therapy & $90.9 \%$ & $93.4 \%$ & & 0.571 & 191 \\
\hline Serum lgE level (kU/l) & $457.8 \pm 991.1(0-5000)$ & $620.8 \pm 2455.0(0-26973)$ & 0.516 & & 190 \\
\hline Long-acting $\beta 2$ agonist & $100 \%$ & $89.3 \%$ & & 0.009 & 191 \\
\hline $\begin{array}{l}\text { Short-acting } \beta 2 \text { agonist } \\
\text { (puffs per day) }\end{array}$ & $3.1 \pm 3.8(0-20)$ & $1.4 \pm 2.8(0-20)$ & 0.002 & & 191 \\
\hline Systemic steroids & $43.3 \%$ & $19.1 \%$ & & $<0.001$ & 191 \\
\hline Inhaled steroids & $98.3 \%$ & $93.1 \%$ & & 0.134 & 191 \\
\hline Theophylline & $36.7 \%$ & $15.3 \%$ & & 0.001 & 191 \\
\hline
\end{tabular}

Notes: Asthma patients belonging to cluster I or 2 are characterized by indicated parameters. Percentages show the fraction of patients fulfilling indicated parameters/ characteristics. Age, Age of onset, Pack years, BMI, serum IgE level and Short-acting $\beta 2$ agonist are presented as mean \pm SD (range). Asthma exacerbation is presented as mean \pm SD.

Abbreviations: ATS, American Thoracic Society; BMI, body mass index; FC, fully controlled; IgE, immunoglobulin E; NC, not controlled; PC, partly controlled. 
classify these patients as atopic or non-atopic, we evaluated their medical history, and skin prick tests were performed with animal dander, food allergens, pollens, fungi, and latex. The NIOX system (Aerocrine, Solna, Sweden) was used to measure fractional exhaled nitric oxide (NO) according to the manufacturer's instructions. Blood eosinophils and eosinophil cationic protein (ECP) were analyzed in the laboratory of the high-altitude clinic. All clinical features and examinations were evaluated on the day that the patients arrived in the clinic (entry) and after 3 weeks (discharge) and are shown in Table 1. The multidisciplinary treatment at high altitude, consisting of personalized treatment plans with physiotherapy and education, aimed to achieve full asthma control with the lowest possible dose of asthma medication. The six-item Asthma Control Questionnaire (Junipers symptom score) was used to assess the level of asthma control. ${ }^{14}$ Responses to each item were rated on a six-point scale; the mean was subsequently calculated and ranged between 0 (totally controlled) and 6 (severely uncontrolled). Informed consent was obtained from all asthma patients. The study was approved by the local ethical committees of the Cantons of Grissons and Zürich. Data were stored in a database and analyzed using SPSS 17.0 (SPSS Schweiz AG, Zürich, Switzerland) and Graphpad Prism 4 (GraphPad Software, Inc., La Jolla, CA, USA).

\section{Statistical analysis and cluster formation}

Because the total number of patients was limited to 191 in this study, we divided the asthma patients into two groups by hierarchical cluster analysis. Power analysis calculated a total sample size of 59 patients for each group (effect size $=0.4, \alpha=0.05,1-\beta=0.95)$. Pearson's chi-squared test was used for statistical analyses of categorical variables because the datasets in each cluster were large enough and the values of cluster 1 and 2 are independent. Mann-Whitney $U$ test was used for statistical analyses of cytokine concentrations because they were not normally distributed. Multiple testing correction was performed by the Benjamini and Hochberg false discovery rate test. Unpaired $t$-test analyses were used for clinical and therapy features, and the calculations are shown as mean \pm standard error of the mean. The paired $t$-test was used to compare parameters before and after therapy. $P$-values below 0.05 were considered significant. Cytokines, which were significantly different between the asthma clusters, were used for principal component analysis to reduce the variables to a principal component. Subsequently, receiver operating characteristic (ROC) analysis with the identified principal component was performed.

\section{Cytokine and chemokine measurements}

Serum probes from asthma patients were taken upon entry of the patients and stored at $-80^{\circ} \mathrm{C}$ until they were analyzed. Serum cytokines were quantified by multiplex measurements (Bioplex; Bio-Rad Laboratories, Hercules, CA, USA). Of 48 serum cytokines or chemokines, 36 were in the detection range in at least $50 \%$ of the asthma patients and used for analyses.

\section{Results \\ Classification of asthma patients according to markers for clinical asthma severity and treatment response}

Asthma patients were classified according to Junipers symptom score, $\mathrm{FEV}_{1}$, serum ECP, circulating eosinophils, and the improvement in $\mathrm{FEV}_{1}$, ECP, and circulating eosinophils after 3 weeks of therapy in the high-altitude clinic in DavosWolfgang. Using hierarchical cluster analysis, two clusters of asthma patients were obtained (Figure 1A). Asthma patients in cluster $1(\mathrm{n}=60)$ had significantly higher Junipers symptom scores, lower $\mathrm{FEV}_{1}$ values, higher ECP serum levels, and a tendency towards higher blood eosinophils than asthma patients in cluster $2(n=131)$ on the day they arrived in the clinic (Figure 1B). The response to asthma therapy differed between these two groups. Asthma patients in cluster 1 showed a higher $\mathrm{FEV}_{1}$ improvement, blood eosinophil decrease, and serum ECP decrease after 3 weeks of intensive asthma therapy (Figure 1C).

\section{Characterization of asthma patients in clusters I and 2}

Asthma patients in clusters 1 and 2 were further characterized by physical examination results, medications, and questionnaire data. The frequency of asthma patients fulfilling American Thoracic Society criteria (for detailed information see http://www.thoracic.org) for severe asthma was significantly higher in cluster 1 than in cluster 2 . The average age of patients in cluster 1 was higher $(54.4 \pm 12.0$ years $)$ than of those in cluster 2 ( $48.1 \pm 15.9$ years), the asthma patients in cluster 1 had significantly more asthma exacerbations over the previous 12 months and less well controlled asthma. In addition, asthma patients in cluster 1 received systemic steroids, $\beta 2$-mimetics (long and short acting), and theophylline as asthma medications more frequently as at the day of entry. There was no difference between these two groups in terms of age of onset, sex, exposure to cigarette smoke, body mass index, serum IgE levels, allergic sensitization, adherence to therapy, and therapy with inhaled steroids (see Table 1). 
A
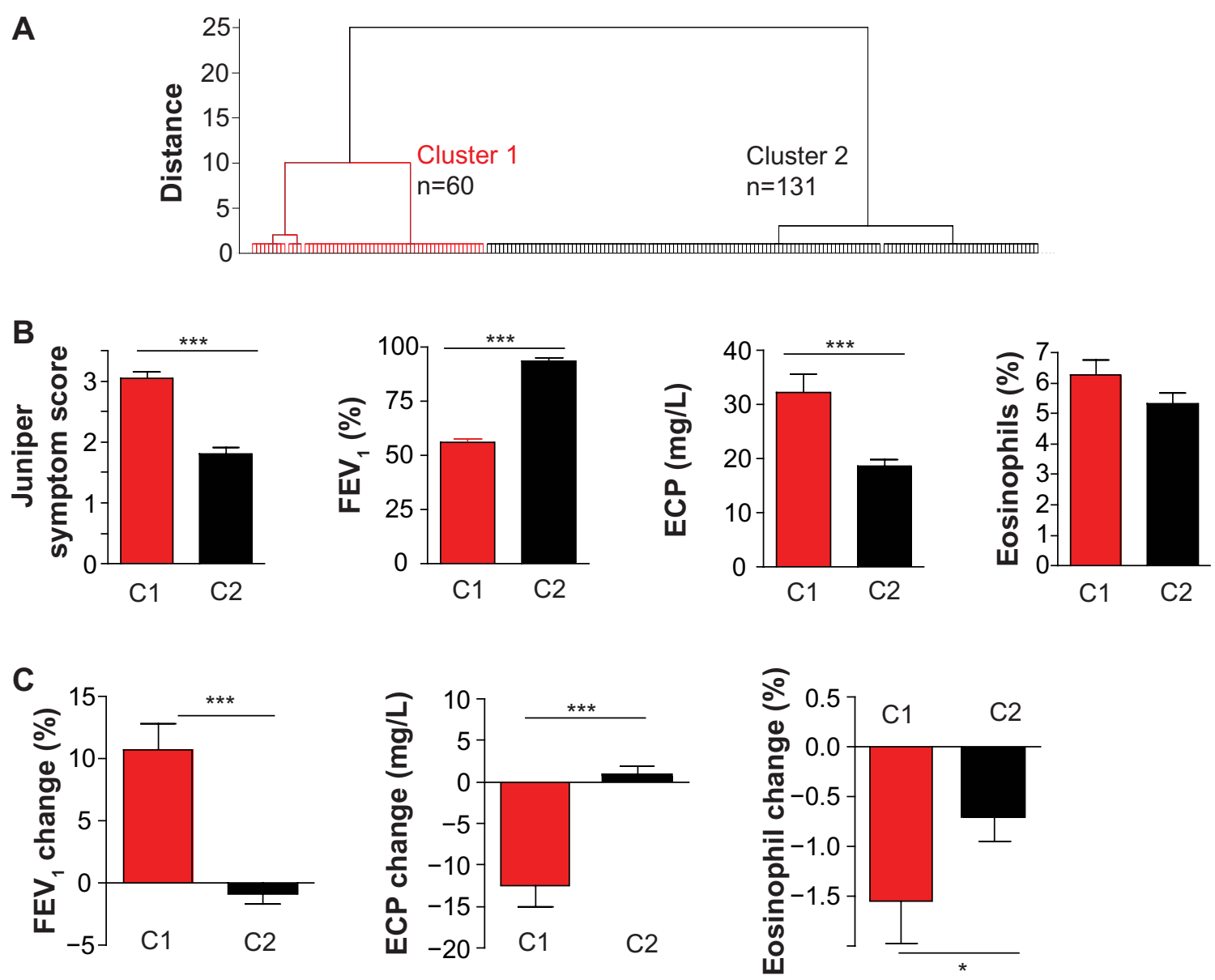

Figure I Classification of asthma patients according to airway inflammation.

Notes: 191 asthma patients were classified by hierarchical cluster analysis with indicated parameters. (A) Dendrogram. (B) At entry to the high-altitude clinic, FEV values, ECP and blood eosinophil levels, and Junipers asthma symptom score were evaluated for cluster I and 2. (C) Changes in FEV , ECP, and blood eosinophils after 3 weeks of asthma therapy from cluster I and 2. CI: asthma patients in cluster I; $C 2$ : asthma patients in cluster 2 ; $* P<0.05$, $* * * P<0.00$; unpaired $t$-test was used.

Abbreviations: $\mathrm{ECP}$, eosinophil cationic protein; $\mathrm{FEV}_{1}$, forced expiratory volume in I second; $n$, number of asthma patients.

To further specify the response to asthma therapy, $\mathrm{FEV}_{1}$, serum ECP, blood eosinophils, and exhaled NO were measured on the day of entry and at discharge after 3 weeks. $\mathrm{FEV}_{1}$ increased significantly from $56.0 \% \pm 13.6 \%$ to $66.7 \% \pm 19.1 \%$ in asthma patients belonging to cluster 1 , whereas there was no significant change in $\mathrm{FEV}_{1}$ in asthma patients in cluster 2 (entry $93.8 \% \pm 16.3 \%$; discharge $92.9 \% \pm 18.2 \%$, Figure $2 \mathrm{~A}$ ). In addition, ECP serum levels decreased from $32.3 \pm 25.8 \mu \mathrm{g} / \mathrm{L}$ to $19.8 \pm 16.2 \mu \mathrm{g} / \mathrm{L}$ in asthma patients in cluster 1 , whereas they did not change for those in cluster 2 (entry $18.7 \pm 12.5 \mu \mathrm{g} / \mathrm{L}$, discharge $19.4 \pm 13.9 \mu \mathrm{g} / \mathrm{L}$, Figure 2A). Blood eosinophils and exhaled NO significantly decreased in both groups after 3 weeks of therapy. Concerning asthma medication, there was no significant change in systemic steroids, inhaled steroids, and long-acting $\beta 2$ agonists between entry and discharge in both clusters, whereas the frequency of short-acting $\beta 2$ agonist usage decreased significantly in both groups after asthma therapy (Figure 2B).
Taken together, asthma patients in cluster 1 are characterized by a less well controlled disease and better response to asthma therapy than asthma patients in cluster 2 .

\section{Increased serum inflammatory protein levels in asthma patients between cluster I and cluster 2}

Next, inflammatory serum protein levels in all asthma patients were analyzed. IL-8, eotaxin, VEGF, cutaneous T-cell-attracting chemokine (CTACK), growth-related oncogene (GRO)- $\alpha$, and hepatocyte growth factor (HGF) in the sera of asthma patients belonging to cluster 1 were significantly higher than in patients in cluster 2 (Figure 3A; for full names of the following cytokines and chemokines, see Table S1). There was no significant difference in IL-1Ra, IL-2, -4, -6, -9, -10, -13, -15, -16, -17, -18, IFN- $\gamma$, TNF- $\alpha$, MIP- $1 \alpha$, MIP- $1 \beta$, MIF, MIG, SCF, SCGF $\beta$, G-CSF, IFN- $\alpha$, LIF, MCP-3, MCSF, FGF, SDF-1 $\alpha$, MCP-1, IP-10, and TRAIL levels (see Table S1). 
A

Cluster 1

Cluster 2
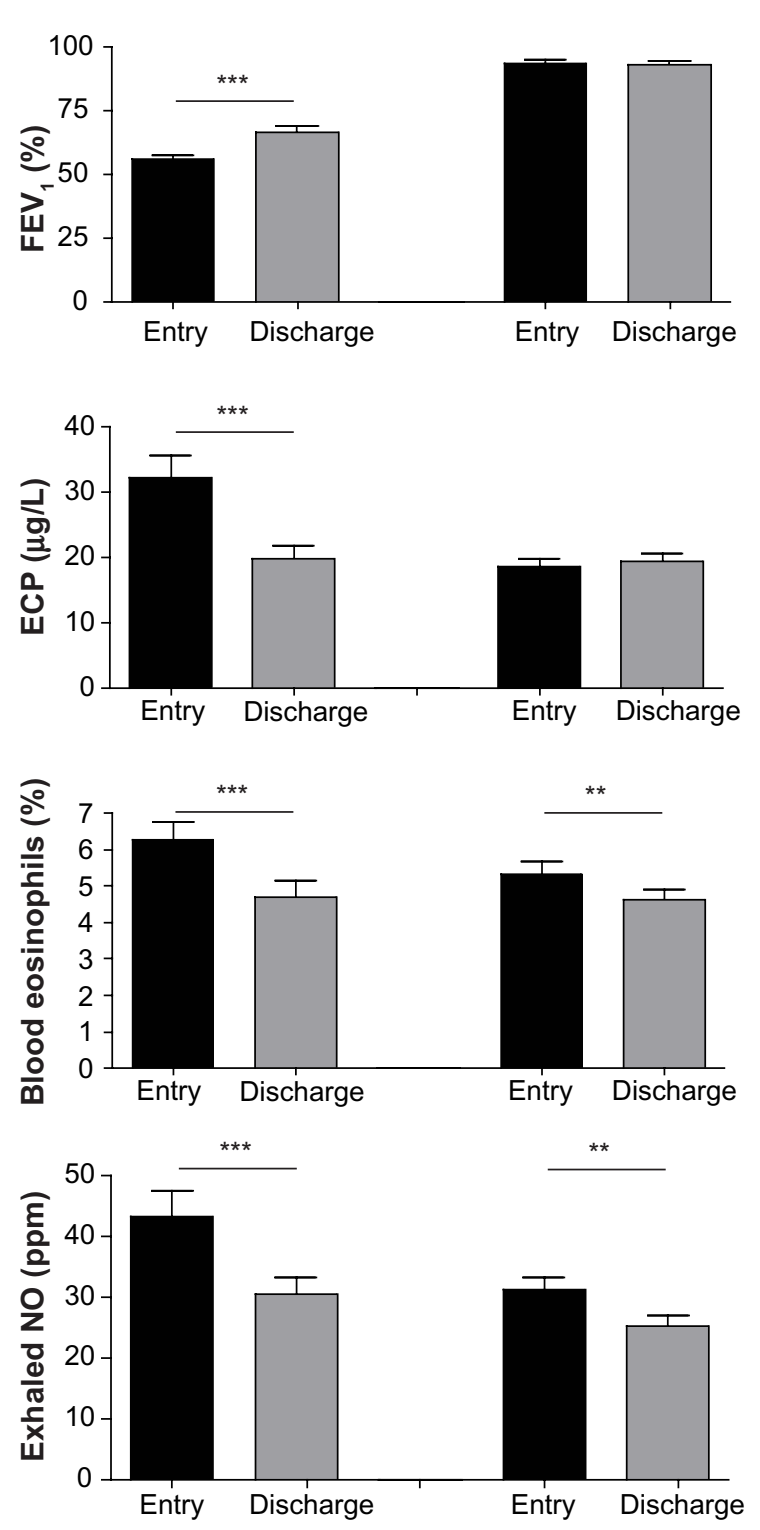

B

Cluster 1

Cluster 2

을
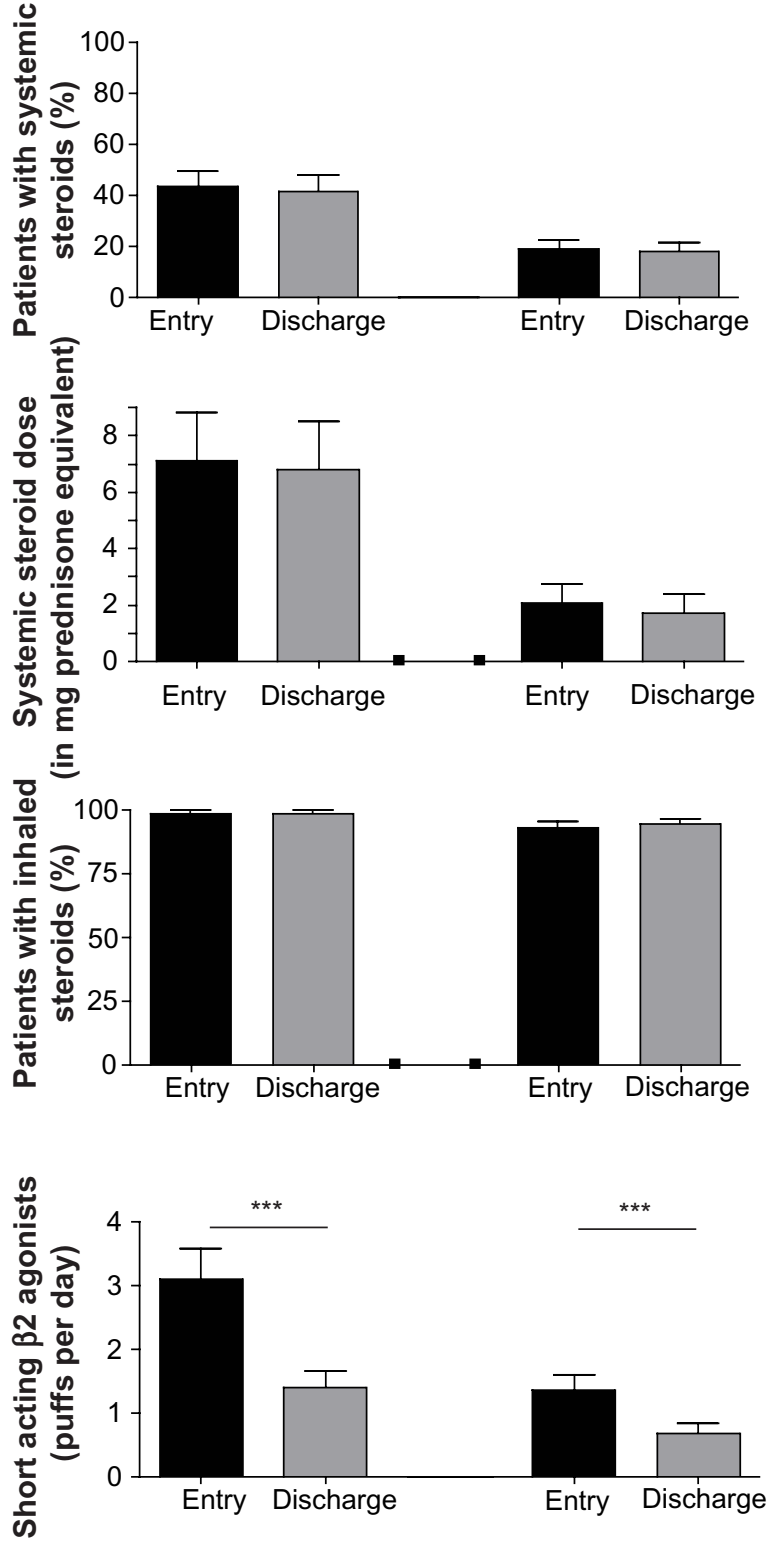

Figure 2 Asthma patients in cluster I respond better to asthma therapy.

Notes: (A) FEV , serum ECP levels, blood eosinophil levels and exhaled NO at the beginning of the high altitude stay (entry) and after 3 weeks (discharge). (B) Fraction of patients with systemic steroids and inhaled steroids, systemic steroid dose and frequency of inhaled short acting $\beta 2$ agonist usage. The paired $t$-test was used to compare changes in indicated parameters between entry and discharge. $* * P<0.01 ; * * *<<0.001$.

Abbreviations: $\mathrm{ECP}$, eosinophil cationic protein; $\mathrm{FEV}_{1}$, forced expiratory volume in I second; $\mathrm{n}$, number of asthma patients; $\mathrm{NO}$, nitric oxide.

Principal component analysis of the concentrations of all cytokines and chemokines that are upregulated in cluster 1 was performed. An ROC for the principal component revealed a sensitivity of $55.9 \%$ and a specificity of $75.8 \%$ for distinguishing between asthma patients in clusters 1 and 2 (area under the curve [AUC] 0.683; Figure 4A). The AUC for single cytokines was lower than the principal component analysis of all upregulated cytokines in cluster 1 (AUC IL-8: 0.645; CTACK: 0.639; eotaxin: 0.640; GRO $\alpha$ : 0.632; HGF: 0.625; VEGF: 0.627; Figure 4B). In addition, there is a significant negative correlation between cytokine serum levels of the upregulated cytokines in cluster 1 and $\mathrm{FEV}_{1}$ (Figure 4C).

\section{Discussion}

Using hierarchical cluster analysis with the clinical routine parameters $\mathrm{FEV}_{1}$, ECP serum levels, blood eosinophil levels, or Junipers asthma symptom score, we were able to classify our population of asthma patients into two groups. One group of asthma patients (cluster 1) was characterized 

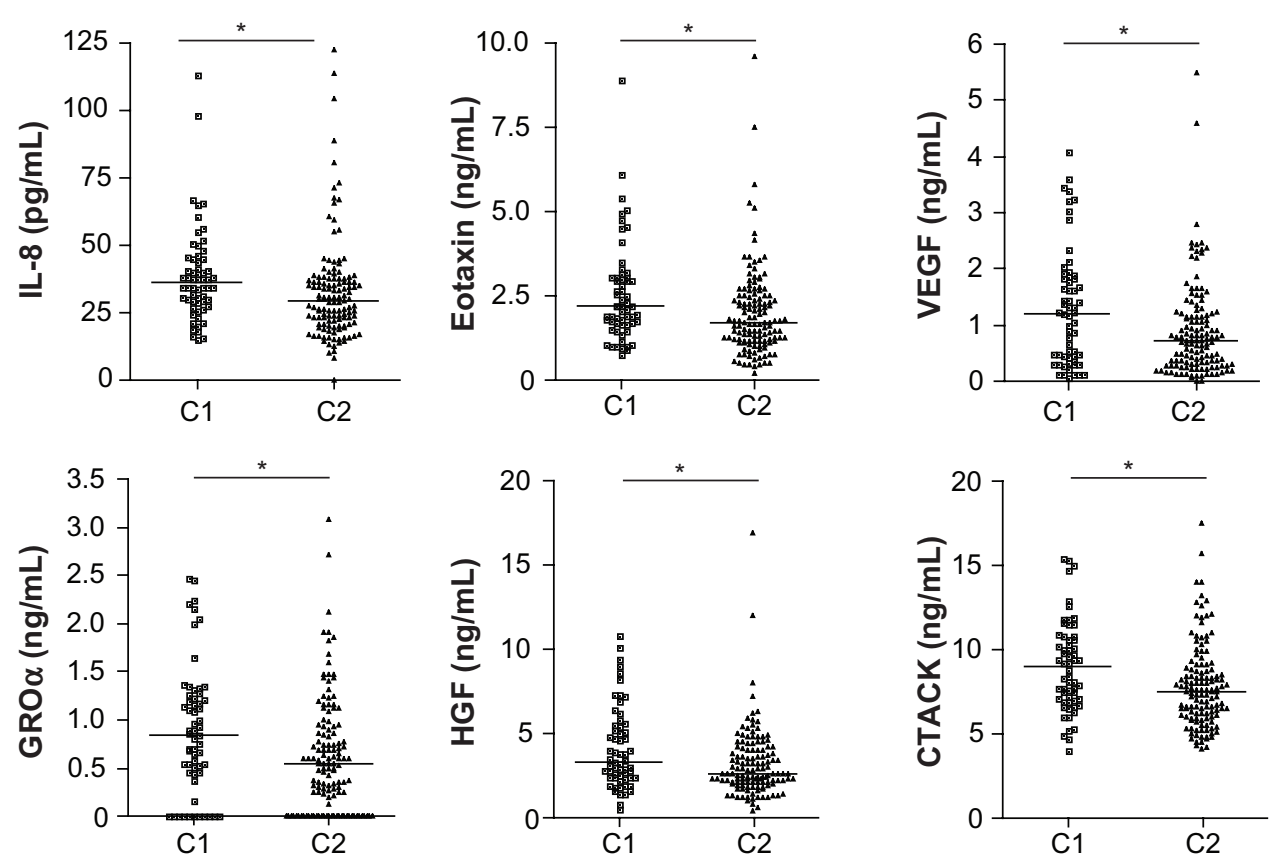

Figure 3 Upregulation of serum cytokines and chemokines in asthma patients belonging to cluster I.

Notes: Serum levels of IL-8, eotaxin, VEGF, CTACK, GRO $\alpha$, and HGF in patients belonging to cluster I or to cluster 2 are shown. Mann-Whitney $U$ test was used. $* P<0.05$.

Abbreviations: CTACK, cutaneous T-cell-attracting chemokine; GRO, growth-related oncogene; HGF, hepatocyte growth factor; IL, interleukin; VEGF, vascular endothelial growth factor.

by higher ECP serum levels, higher numbers of circulating eosinophils, lower $\mathrm{FEV}_{1}$ values, and better response to asthma therapy. Further characterization of these asthma patients demonstrated that they had less well controlled asthma with more exacerbations over the previous year. Importantly, these asthma patients had higher serum levels of certain pro-inflammatory cytokines and chemokines. In addition, the profile of serum cytokines could predict, with a sensitivity of $55.9 \%$ and specificity of $75.8 \%$, the cluster to which asthma patients belonged.

Asthma is a heterogeneous disease, which could be divided into subgroups according to therapy response, fixed airway obstruction, obesity, or trigger factors such as allergens, air pollution, occupational irritants, cigarette smoke, aspirin, and exercise..$^{15}$ The identification of asthma phenotype-specific inflammatory pathways is one important
A

Cytokines cluster 1 versus cluster 2

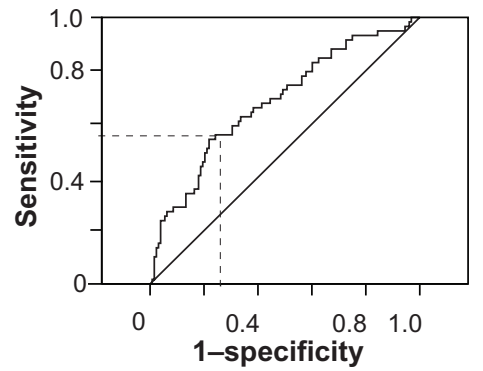

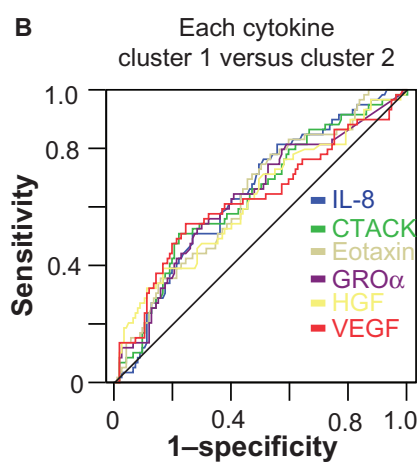

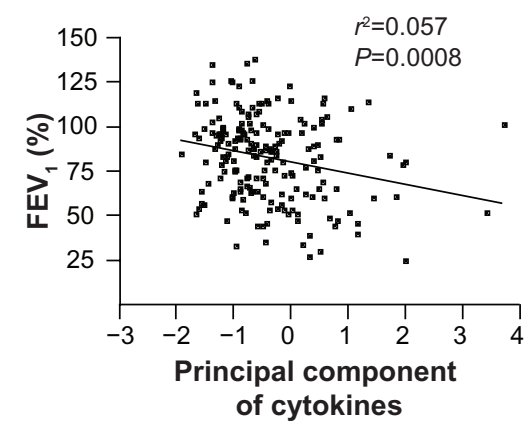

Figure 4 Prognostic value of serum cytokines to distinguish between asthma patients belonging to cluster I or 2 .

Notes: ROC for the principal component of the serum cytokines IL-8, eotaxin, VEGF, CTACK, GRO $\alpha$, and HGF to distinguish between cluster I and 2 was analyzed. (A) Area under the curve produced a sensitivity of $55.9 \%$ and a specificity of $75.8 \%$ to discriminate between asthma patients from cluster I and cluster 2 . (B) ROC analyses of the single cytokines. (C) There is a negative correlation between cytokine expression assessed by the principal component analyses of the serum cytokines upregulated in cluster I and FEV, values.

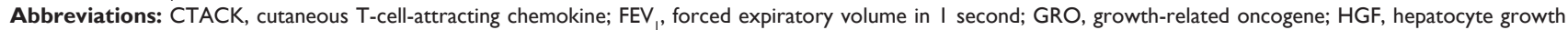
factor; IL, interleukin; ROC, receiver operating characteristic; VEGF, vascular endothelial growth factor. 
approach to improve the diagnosis and treatment of asthma. In this context, the term endotype ${ }^{16}$ was recently introduced, which suggests that asthma phenotypes are characterized by certain inflammatory mechanisms, which correlate with treatment response. ${ }^{1}$ Accordingly, we classified the asthma patients into two groups by parameters used routinely in our clinic and that reflected clinical asthma severity and response to asthma treatment. Serum cytokine and chemokine levels were measured to investigate if different inflammatory pathways were activated in asthma patients from clusters 1 and 2. Interestingly, in asthma patients from cluster 1, higher serum levels of IL-8, eotaxin, VEGF, CTACK, GRO $\alpha$, and HGF were present, indicating that different inflammatory and molecular mechanisms were activated. In addition, IL-17 had the tendency to be elevated in cluster 1 compared with cluster 2. Serum IL-17 is elevated in severe asthma ${ }^{11}$ and amplifies local airway inflammation by induction of IL-6 in bronchial epithelial cells ${ }^{17}$ or IL-8 in human airway epithelial cells. ${ }^{18}$ IL-17 and Th2 cytokine-producing T-cells also promote asthmatic inflammation via the upregulation of eotaxin in bronchial epithelial cells. ${ }^{19}$ In addition, in bronchial biopsies from asthmatic patients, there is a high expression of $\mathrm{VEGF},{ }^{20}$ which is a key regulator of blood vessel growth in the airways of asthma patients via the promotion of proliferation and differentiation of endothelial cells and inducing vascular leakage and increased permeability. ${ }^{21}$ One possible explanation for elevated inflammation-related cytokines and chemokines in the sera of asthma patients with lower $\mathrm{FEV}_{1}$ values and more frequent exacerbations may be that airway inflammation may lead to the generation of large amounts of cytokines, which may enter into the circulation, resulting in elevated serum concentrations. Therefore, the upregulation of certain cytokines and chemokines in the sera may be an indicator for physicians to optimize or initiate asthma treatment. Interestingly, asthma patients in cluster 1 and 2 were all mostly compliant with the medication therapy, indicating that the $\mathrm{FEV}_{1}$ improvement in asthma patients with clinically more severe asthma (cluster 1) might be due to treatment optimization and not to an improvement in medication compliance.

Although treatment management of asthma patients by measurement of sputum eosinophils could decrease the number of asthma exacerbations and steroid dose, ${ }^{22}$ eosinophils may not be useful in the prediction of exacerbations for all asthma types because, besides eosinophilic asthma, neutrophilic, mixed granulocytic, and paucigranulocytic asthma subgroups also exist. ${ }^{23}$ In addition, the induction of induced sputa may not be technically possible in all asthma patients.
Analysis of serum eosinophils is a simple method that is routinely undertaken for asthma patients. However, in our study, serum eosinophils were not significantly elevated in patients with clinically more severe asthma (cluster 1) in contrast with the identified serum proteins, suggesting that they are also upregulated in exacerbated non-eosinophilic asthma. The higher levels of pro-inflammatory cytokines and chemokines in the serum indicate asthma patients with poorly controlled asthma. Therefore, measuring serum cytokines as a diagnostic tool might be useful for the optimization of asthma treatment. However, this study has not assessed the direct effect of asthma medications on serum cytokines. Therefore, the effect of asthma treatment on the serum cytokines upregulated in cluster 1 should be investigated in future studies. Less invasive methods for the assessment of local airway inflammation include analysis of nitrates ${ }^{24}$ or $\mathrm{pH}$ values ${ }^{25}$ in exhaled breath condensates, which are related to asthma control and may be interesting tools for asthma management in the future. These methods may also be combined with the measurement of serum cytokines and chemokines.

Repeated airway inflammation causes structural airway changes, known as airway remodeling, including smooth muscle hypertrophy, goblet cell hyperplasia, subepithelial fibrosis, and angiogenesis..$^{21}$ These structural changes influence the reversibility of airway obstruction and increase disease severity. ${ }^{26}$ Inflammatory markers, which can predict the severity of airway inflammation, could be important for optimal asthma treatment decisions to avoid airway remodeling caused by chronic inflammation. We demonstrate that certain serum cytokines and chemokines could identify asthma patients with clinically more severe asthma and better treatment response.

\section{Conclusion}

Certain pro-inflammatory serum cytokines and chemokines are important markers for the severity and activity of asthma, asthma control, and treatment response. The assessment of systemic immune response by serum levels of cytokines and chemokines in asthma patients might be an important tool for monitoring asthma patients and for asthma therapy optimization.

\section{Disclosure}

The NM, CAA and GM are supported by the European Allergy and Asthma Center Davos (EACD), SNF grants No 32-132899 and the Christine Kühne Center for Allergy Research and Education (CK-CARE). 


\section{References}

1. Lötvall J, Akdis CA, Bacharier LB, et al. Asthma endotypes: a new approach to classification of disease entities within the asthma syndrome. J Allergy Clin Immunol. 2011;127(2):355-360.

2. Kim HY, DeKruyff RH, Umetsu DT. The many paths to asthma: phenotype shaped by innate and adaptive immunity. Nat Immunol. 2010;11(7):577-584.

3. Robinson DS, Hamid Q, Ying S, et al. Predominant TH2-like bronchoalveolar T-lymphocyte population in atopic asthma. N Engl J Med. 1992;326(5):298-304.

4. Walker C, Bauer W, Braun RK, et al. Activated T cells and cytokines in bronchoalveolar lavages from patients with various lung diseases associated with eosinophilia. Am J Respir Crit Care Med. 1994;150(4): 1038-1048.

5. Akdis CA, Akdis M. Mechanisms and treatment of allergic disease in the big picture of regulatory T cells. J Allergy Clin Immunol. 2009;123(4): 735-746; quiz 747-748.

6. Palomares O, Yaman G, Azkur AK, Akkoc T, Akdis M, Akdis CA. Role of Treg in immune regulation of allergic diseases. Eur J Immunol. 2010;40(5):1232-1240.

7. Wiehler S, Proud D. Interleukin-17A modulates human airway epithelial responses to human rhinovirus infection. Am J Physiol Lung Cell Mol Physiol. 2007;293(2):L505-L515.

8. Hellings PW, Kasran A, Liu Z, et al. Interleukin-17 orchestrates the granulocyte influx into airways after allergen inhalation in a mouse model of allergic asthma. Am J Respir Cell Mol Biol. 2003;28(1):42-50.

9. Meyer N, Zimmermann M, Bürgler S, et al. IL-32 is expressed by human primary keratinocytes and modulates keratinocyte apoptosis in atopic dermatitis. J Allergy Clin Immunol. 2010;125(4):858-865. e10.

10. Kim JH, Kim JE, Choi GS, Him HY, Ye YM, Park HS. Serum cytokines markers in toluene diisocyanate-induced asthma. Respir Med. 2011;105(7):1091-1094.

11. Agache I, Ciobanu C, Agache C, Anghel M. Increased serum IL-17 is an independent risk factor for severe asthma. Respir Med. 2010;104(8): 1131-1137.

12. Meyer N, Christoph J, Makrinioti H, et al. Inhibition of angiogenesis by IL-32: possible role in asthma. J Allergy Clin Immunol. 2012;129(4): 964-973. e7.

13. Pukelsheim K, Stoeger T, Kutschke D, Ganguly K, Wjst M. Cytokine profiles in asthma families depend on age and phenotype. PLoS One. 2010;5(12):e14299.
14. Juniper EF, O’Byrne PM, Guyatt GH, Ferrie PJ, King DR. Development and validation of a questionnaire to measure asthma control. Eur Respir J. 1999;14(4):902-907.

15. Balzar S, Strand M, Nakano T, Wenzel SE. Subtle immunodeficiency in severe asthma: $\operatorname{IgA}$ and $\operatorname{IgG} 2$ correlate with lung function and symptoms. Int Arch Allergy Immunol. 2006;140(2):96-102.

16. Anderson GP. Endotyping asthma: new insights into key pathogenic mechanisms in a complex, heterogeneous disease. Lancet. 2008;372(9643):1107-1119.

17. Burgler S, Ouaked N, Bassin C, et al. Differentiation and functional analysis of human $\mathrm{T}(\mathrm{H}) 17$ cells. J Allergy Clin Immunol. 2009;123(3):588-595,595. e1-e7.

18. Jones CE, Chan K. Interleukin-17 stimulates the expression of interleukin-8, growth-related oncogene-alpha, and granulocyte-colonystimulating factor by human airway epithelial cells. Am J Respir Cell Mol Biol. 2002;26(6):748-753.

19. Wang YH, Voo KS, Liu B, et al. A novel subset of CD4(+) $\mathrm{T}(\mathrm{H}) 2$ memory/effector cells that produce inflammatory IL-17 cytokine and promote the exacerbation of chronic allergic asthma. J Exp Med. 2010;207(11):2479-2491.

20. Hoshino M, Nakamura Y, Hamid QA. Gene expression of vascular endothelial growth factor and its receptors and angiogenesis in bronchial asthma. J Allergy Clin Immunol. 2001;107(6):1034-1038.

21. Detoraki A, Granata F, Staibano S, Rossi FW, Marone G, Genovese A. Angiogenesis and lymphangiogenesis in bronchial asthma. Allergy. 2010;65(8):946-958.

22. Green RH, Brightling CE, McKenna S, et al. Asthma exacerbations and sputum eosinophil counts: a randomised controlled trial. Lancet. 2002;360(9347):1715-1721.

23. Simpson JL, Scott R, Boyle MJ, Gibson PG. Inflammatory subtypes in asthma: assessment and identification using induced sputum. Respirology. 2006;11(1):54-61.

24. Malinovschi A, Pizzimenti S, Sciascia S, Heffler E, Badiu I, Rolla G. Exhaled breath condensate nitrates, but not nitrites or FENO, relate to asthma control. Respir Med. 2011;105(7):1007-1013.

25. Kostikas K, Papaioannou AI, Tanou K, et al. Exhaled NO and exhaled breath condensate $\mathrm{pH}$ in the evaluation of asthma control. Respir Med. 2011;105(4):526-532.

26. Tillie-Leblond I, de Blic J, Jaubert F, Wallaert B, Scheinmann P, Gosset P. Airway remodeling is correlated with obstruction in children with severe asthma. Allergy. 2008;63(5):533-541. 


\section{Supplementary material}

Table SI Serum cytokine and chemokine levels in asthma patients belonging to cluster $\mathrm{I}$ or to cluster 2

\begin{tabular}{|c|c|c|c|}
\hline & Cluster I & Cluster 2 & $P$-value \\
\hline IL-IRa & $\mathrm{I}, 465.7 \pm I, 74 \mathrm{I} .6$ & $1,927.3 \pm 3,958.4$ & 0.34 \\
\hline IL-2 & $62.8 \pm 97.0$ & $90.4 \pm 334.3$ & 0.34 \\
\hline IL-4 & $67.9 \pm 24.8$ & $63.1 \pm 26.9$ & 0.14 \\
\hline IL-9 & $864.1 \pm 2,783.0$ & $631.1 \pm 3,446.8$ & 0.23 \\
\hline $\mathrm{IFN}-\gamma$ & $2,057.1 \pm 2,207.5$ & $2,070.8 \pm 3,370.4$ & 0.15 \\
\hline MIP-I $\beta$ & $510.5 \pm 509.2$ & $I, 228 . I \pm 858.3$ & 0.19 \\
\hline TNF- $\alpha$ & $237.4 \pm 217.1$ & $262.8 \pm 348.5$ & 0.31 \\
\hline IL-2Ra & $1,016.5 \pm 1,140.8$ & $676.4 \pm 574.2$ & 0.06 \\
\hline IL-I8 & $643.5 \pm 361.6$ & $568.9 \pm 324.1$ & 0.11 \\
\hline MIF & $|, 254| .2 \pm 7,7 \mid 3.4$ & $10,153.0 \pm 5,276.7$ & 0.10 \\
\hline MIG & $13,156.3 \pm 19,172.1$ & $9,572.8 \pm 19,840.7$ & 0.10 \\
\hline SCF & $894.2 \pm 4 \mid 8.2$ & $804.4 \pm 326.6$ & 0.21 \\
\hline SCGF $\beta$ & $199,001.3 \pm 133,999.6$ & $|59,837.8 \pm| 07,284 . \mid$ & 0.06 \\
\hline G-CSF & $211.0 \pm 213.8$ & $184.0 \pm 202.8$ & 0.34 \\
\hline FGF & $232.6 \pm 262.8$ & $206.6 \pm 298.4$ & 0.33 \\
\hline IL-6 & $62.7 \pm 70.9$ & $62.5 \pm 142.5$ & 0.08 \\
\hline IL-I0 & $57.8 \pm 291.0$ & $36.2 \pm 134.7$ & 0.09 \\
\hline IL-I5 & $41.1 \pm 62.8$ & $26.9 \pm 57.1$ & 0.07 \\
\hline MIP-I $\alpha$ & $26.2 \pm 25.7$ & $20.3 \pm 23.5$ & 0.05 \\
\hline IFN- $\alpha$ & $39.8 \pm 116.7$ & $18.5 \pm 65.4$ & 0.16 \\
\hline LIF & $86.7 \pm 557.1$ & $12.5 \pm 27.9$ & 0.36 \\
\hline MCP-3 & $146.4 \pm 956.3$ & $47.9 \pm 154.1$ & 0.83 \\
\hline MCSF & $27.6 \pm 61.0$ & $22.0 \pm 58.3$ & 0.32 \\
\hline SDF-I $\alpha$ & $189.1 \pm 3 \mid 5.1$ & $151.6 \pm 264.9$ & 0.52 \\
\hline IL-I3 & $43.9 \pm 87.9$ & $36.2 \pm 75.5$ & 0.06 \\
\hline
\end{tabular}

Notes: Serum levels of cytokines and chemokines, which were not significantly different between cluster $I$ and cluster 2 are shown. Mann-Whitney $U$ test was used. Concentrations are shown in $\mathrm{pg} / \mathrm{mL} \pm \mathrm{SD}$.

Abbreviations: IL, interleukin; IFN- $\gamma$, gamma-interferon; MIP-I $\beta$, macrophage inflammatory protein I beta; TNF- $\alpha$, tumor necrosis factor-alpha; MIF, macrophage migration inhibitory factor; MIG, monokine-induced by interferon-gamma; SCF, stem cell factor; SCGF $\beta$, stem cell growth factor beta; G-CSF, granulocyte colonystimulating factor; FGF, fibroblast growth factor; MIP-I $\alpha$, macrophage inflammatory protein I alpha; IFN- $\alpha$, alpha-interferon; LIF, leukemia inhibitory factor; MCP-3, monocyte chemotactic protein-3; MCSF, macrophage colony-stimulating factor; SDF-I $\alpha$, stromal cell-derived factor-I alpha; SD, standard deviation.

\section{Publish your work in this journal}

The Journal of Asthma and Allergy is an international, peer-reviewed open-access journal publishing original research, reports, editorials and commentaries on the following topics: Asthma; Pulmonary physiology; Asthma related clinical health; Clinical immunology and the immunological basis of disease; Pharmacological interventions and

\section{Dovepress}

new therapies. Issues of patient safety and quality of care will also be considered. The manuscript management system is completely online and includes a very quick and fair peer-review system, which is all easy to use. Visit http://www.dovepress.com/testimonials.php to read real quotes from published authors. 